\title{
Exergy Analysis of a Residential Building in Southern Italy: Lessons for Low-Exergy Buildings and Systems
}

\author{
Gianpiero Evola, Vincenzo Costanzo, Luigi Marletta \\ University of Catania, DIEEI, Viale Andrea Doria 6, 95125 Catania, Italy
}

\begin{abstract}
The energy performance of energy systems in buildings is commonly studied by applying the First Law of Thermodynamics, which allows to quantify the energy losses and to measure the energy conversion efficiency of the single components. However, different forms of energy have different potential to produce useful work, mainly depending on the temperature at which they are available. For this reason, the Second Law of Thermodynamics should be also considered.

The main scope of this paper is to apply the exergy analysis to a residential building located in Southern Italy, including its energy systems. The calculation is based on a quasi-steady-state approach, where dynamic simulations are used to describe the energy performance of the building, and steady-state equations are used to assess the exergy flows. The selected residential building contains eight dwellings, heated by a conventional gas boiler and cooled by individual split-units; however, the calculations refer to only one apartment.

The outcomes of this simulation effort show that the exergy efficiency for space heating and cooling in the current state is very low, being of $6.2 \%$ and 3.8\% respectively. This is mainly due to the use of combustion processes for producing heat, and to the use of electricity (i.e. pure exergy) to feed the cooling systems. However, the implementation of typical refurbishment strategies such as improving the insulation of the envelope and adopting more performing mechanical systems, not only reduces the energy needs for heating and cooling by around $20 \%$, but also raises the exergy efficiency for heating and cooling up to $13.1 \%$ and $6.2 \%$, respectively.
\end{abstract}

\section{Introduction}

According to the First Law of Thermodynamics, in a steady-state energy conversion process the overall energy flow leaving a system equals the overall energy flow entering the same system. The different forms of energy (thermal, mechanical, internal, potential, kinetic, electric, and chemical) may individually undergo quantitative changes, but the overall amount of energy involved in the process is conserved. The index of performance resulting from this approach is the energy efficiency, which is the ratio of the useful amount of energy provided by the process to the total amount of energy exploited by the system.
However, the Second Law of Thermodynamics shows that the different forms of energy involved in a process have not the same quality, since they have different potential to produce useful work. In particular, the useful work potentially extracted from a system at a given thermodynamic state can be measured by letting the system evolve to a condition of thermal and pressure equilibrium with the surrounding environment. In this final condition, no further change of state occurs spontaneously, and no further work can be produced; the system is then said to be in the dead state.

In this framework, exergy can be defined as the maximum amount of work that it is possible to produce by exploiting a system or an energy flow available at a certain temperature and pressure, through an ideal reversible process evolving until the dead state is reached. Accordingly, the further the temperature of the system is from the environmental temperature, the higher the exergy of the system is.

Several lessons can be learned by applying the exergy analysis to the building sector, where the delivery or removal of thermal energy is required, respectively, in space heating and cooling applications, as well as to prepare domestic hot water (DHW). Indeed, in space heating systems, thermal energy is delivered to indoor spaces at a temperature of around $20{ }^{\circ} \mathrm{C}$, which is very close to the outdoor environment (dead state); similar reasoning can be applied to thermal energy removed in space cooling applications. This means that the quality of the energy required for applications in space air conditioning is low; nevertheless, heating and cooling systems in buildings are frequently operated at high temperatures, and they use high-quality energy sources, such as fuels and electricity.

Recently, the exergy analysis of buildings and their energy conversion systems has been investigated by a growing number of studies. In fact, the most relevant contribution has come from the IEA ECBCS Annex 49 "Low Exergy Systems for High-Performance Buildings and Communities", whose activities were concluded in 2009. ECBCS Annex 49 involved about 22 research institutes, universities and private companies from 12 different countries, many of which were also members of the International Society of Low Exergy Systems in Buildings (LowExNet) (Schmidt, 2011).

Some interesting papers can also be cited. As an example, (Zhou and Gong, 2013) studied a six-storey 
residential building with split-type air conditioners for space heating and cooling. In their study, several possible improvements to the thermal insulation of the envelope and/or potential improvements to the COP of the split units gave rise to an increase in the overall annual exergy efficiency from $5.1 \%$ to $7.9 \%$.

Other studies have also underlined the role played by the auxiliary components, whose impact in the overall balance of low-exergy heating systems is significant. In this sense, some authors have shown a steady-state exergy analysis of several heating systems for a residential unit in Denmark (Kazanci et al., 2016). The results underline that the electricity consumption of a pump operating in a floor heating system is much higher than for common radiators, due to the lower temperature drop and the consequent higher mass flow rate. As a result, the exergy depleted by the system increases, and in certain cases it may overcome the advantage of using low-temperature radiant terminals.

Under these premises, the main scope of this paper is to address these irrational energy uses for space heating and cooling by applying the exergy analysis to a case study, namely a building representative of the residential stock in Catania (Italy).

Dynamic simulations in EnergyPlus are employed to evaluate the energy flows, and the corresponding exergy flows, from the HVAC systems to the indoor spaces and then to the outdoors. The analysis of the building in its current configuration shows that the exergy efficiency is very low, being of $6.2 \%$ for space heating and $3.8 \%$ for space cooling. The implementation of typical retrofit solutions such as improving the insulation level of the envelope and using heat pump systems can raise the exergy efficiency up to $13.1 \%$ in the case of space heating and to $6.2 \%$ for space cooling respectively. The study also underlines that the results of the analysis are severely influenced by the choice of the reference state: this makes the replicability of the exergy analysis questionable, and calls for the definition of an internationally recognised calculation framework.

\section{Case study and methodology}

\section{The case study}

The building selected as a case study is an apartment block with four storeys above the ground located in Catania (Italy), a city characterized by a hot and humid climate with sunny days for most of the year. The main climatic parameters, extracted from the Typical Meteorological Year (TMY) weather file retrieved from the EnergyPlus website, are summarized in Table 1.

As for the building layout, it presents a rectangular shape with dimensions of $18.1 \times 11.8 \mathrm{~m}^{2}$ that result in a gross floor area of $816 \mathrm{~m}^{2}$ and in a useful floor area of around $725 \mathrm{~m}^{2}$ respectively (see Figure 1 for an outdoor view of the north facade). The gross height of each storey is $3 \mathrm{~m}$, resulting in a heated gross volume of around $2500 \mathrm{~m}^{3}$ for the entire building.
Table 1: Main climatic parameters of Catania

\begin{tabular}{lc}
\hline Geographical coordinates & Lat $37^{\circ} 31^{\prime} \mathrm{N}-$ Lon $15^{\circ} 04^{\prime} \mathrm{E}$ \\
\hline Mean daily temperature in summer & $24^{\circ} \mathrm{C}$ \\
\hline Mean peak temperature in summer & $35^{\circ} \mathrm{C}$ \\
\hline Mean daily temperature in winter & $11.8^{\circ} \mathrm{C}$ \\
\hline Mean peak temperature in winter & $-1.9^{\circ} \mathrm{C}$ \\
\hline Mean horizontal daily irradiance & $159.1 \mathrm{~W} \cdot \mathrm{m}^{-2}$ \\
\hline Peak irradiance on the horizontal & $1021 \mathrm{~W} \cdot \mathrm{m}^{-2}$ \\
\hline Mean daily wind speed & $3 \mathrm{~m} \cdot \mathrm{s}^{-1}$ \\
\hline Mean peak wind speed & $13.1 \mathrm{~m} \cdot \mathrm{s}^{-1}$ \\
\hline
\end{tabular}

Table 2: Building envelope characteristics

\begin{tabular}{ccc}
\hline $\begin{array}{c}\text { Building } \\
\text { component }\end{array}$ & Constructions & $\begin{array}{c}\mathbf{U}-\text { value } \\
\left(\mathbf{W ~ m ~}^{-2} \mathbf{K}^{-1}\right)\end{array}$ \\
\hline External walls & $\begin{array}{c}\text { Double-leaf clay bricks } \\
\text { with air gap }\end{array}$ & 0.86 \\
Slabs & $\begin{array}{c}\text { Lightweight concrete } \\
\text { Single-glazed with } \\
\text { aluminium frame }\end{array}$ & 2.72 \\
\hline
\end{tabular}

Each floor hosts two apartments and is organized according to a common internal layout, with a stairwell on the north side from which it is possible to access two flats. Every flat has two or three bedrooms, a kitchen, a living room, two bathrooms, a balcony facing south and a balcony with a veranda facing north (see Figure 2).

The construction technique used for the envelope is typical of the buildings built in the 1970s, which represent the vast majority of the residential stock in Catania. More in detail, the external walls are made of double-leaf hollow clay bricks (8-cm thick on the inner side and $12-\mathrm{cm}$ thick on the outer side, respectively). An air gap of $10 \mathrm{~cm}$ separates the two leafs. As for the slabs, all the floor enclosures are made of a $20-\mathrm{cm}$ thick lightweight concrete slab without any insulating layer.

Internal partitions consist of 8 -cm thick hollow clay bricks covered with 1-cm concrete plaster on both sides, while windows are single-glazed with an aluminum frame and without any thermal break. Table 2 summarizes the technical features of the envelope components, together with their U-values.

Finally, space heating is provided by means of radiators fed by hot water at a nominal temperature of $75{ }^{\circ} \mathrm{C}$ produced by a gas-fired boiler whose thermal efficiency is $\eta=90 \%$; instead, space cooling is provided by several split-type air conditioning devices, whose average Energy Efficiency Ratio is EER $=3$.

\section{Thermal modelling in OpenStudio}

Dynamic energy simulations were carried out through OpenStudio v.2.7.0, which provides a user-friendly graphical interface to the EnergyPlus v.9.0 software (DOE, 2018). In particular, a flat of the middle-storey (the one highlighted with a dashed line and tagged as Apartment 2 in Figure 2) has been modelled as representative of the average behaviour of the entire building, thus neglecting the boundary effects that may be experienced at the bottom and top floors. 


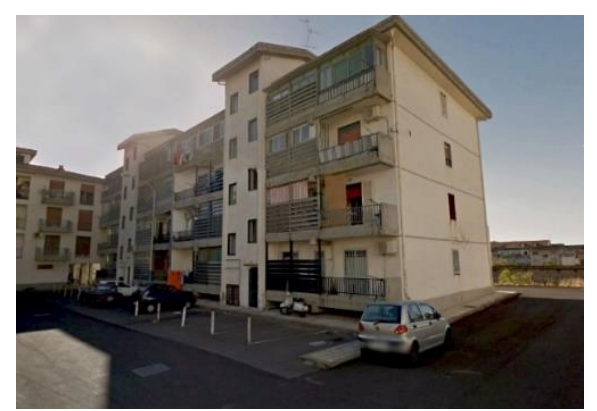

Figure 1: Outdoor view of the building used as a case study

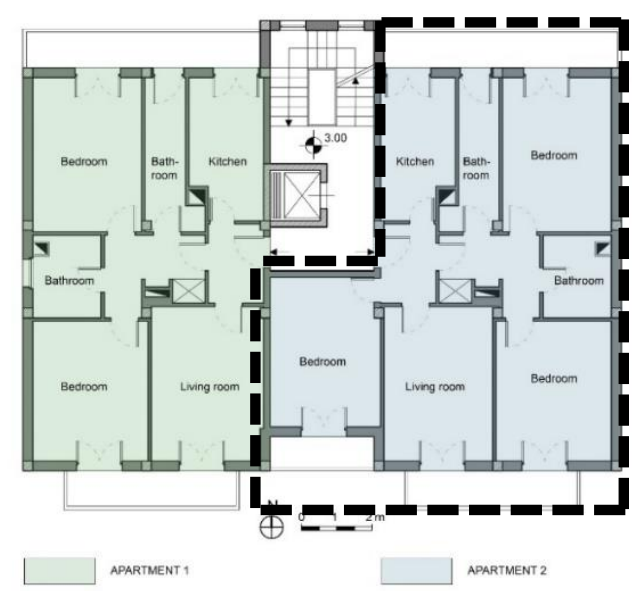

Figure 2: Internal layout of a typical floor. The flat considered in this study is highlighted by a dashed line (right-hand side)

According to this principle, adjoining surfaces with upper and lower apartments are treated as adiabatic. The corresponding model in OpenStudio is shown in Figure 3 , where purple surfaces identify shading objects such as overhead balconies and nearby buildings.

As for air infiltrations, they are computed adopting the Effective Leakage Area (ELA) method proposed by the ASHRAE Handbook Fundamentals (ASHRAE, 2001). This approach first associates a leakage area $A_{L}\left(\mathrm{~cm}^{2}\right)$ to every thermal zone in the building, which summarises the effect of all small cracks in the envelope. The leakage area can be correlated to the net volume $V_{n}\left(\mathrm{~m}^{3}\right)$ and the air-tightness $\mathrm{n}_{50}\left(\mathrm{~h}^{-1}\right)$ of the thermal zones by the following relationship:

$$
A_{L}=\frac{n_{50} \cdot V_{n}}{3600} \cdot \sqrt{\frac{\rho}{2 \cdot \Delta p_{50}}}
$$

Here $\mathrm{n}_{50}$ represents the air exchange rate $\left(\mathrm{h}^{-1}\right)$ occurring when a pressure difference of $50 \mathrm{~Pa}$ is imposed to the envelope (usually through a blower door test). In absence of experimental measurements, this value has been set to $4 \mathrm{~h}^{-1}$, as suggested by the Italian technical standard UNI 11300-1:2014 (UNI, 2014) for multistorey apartment blocks with average air permeability.

Once the leakage area is known, the air flow rate through the envelope because of leakages $\left(Q_{\text {inf }}\right.$, expressed in $\mathrm{m}^{3} \cdot \mathrm{s}^{-1}$ ) can be computed according to the following equation:

$$
\mathrm{Q}_{\mathrm{inf}}=\frac{\mathrm{A}_{\mathrm{L}}}{1000} \cdot \sqrt{\mathrm{C}_{\mathrm{S}} \cdot \Delta \mathrm{T}+\mathrm{C}_{\mathrm{W}} \cdot \mathrm{w}^{2}}
$$

This approach accounts for both the stack and wind effects by means of the coefficients $\mathrm{C}_{\mathrm{S}}\left(1 \cdot \mathrm{S}^{-1}\right)^{2} \cdot\left(\mathrm{cm}^{4} \cdot \mathrm{K}\right)^{-1}$ and $\mathrm{C}_{\mathrm{W}}\left(1 \cdot \mathrm{s}^{-1}\right)^{2} \cdot\left(\mathrm{cm}^{4} \cdot \mathrm{m}^{2} \cdot \mathrm{s}^{-2}\right)^{-1}$, which are defined as a function of the building location, its number of floors and the surrounding building density. In our case, their values are set to $\mathrm{C}_{\mathrm{S}}=1.45 \times 10^{-4}\left(1 \cdot \mathrm{s}^{-1}\right)^{2} \cdot\left(\mathrm{cm}^{4} \cdot \mathrm{K}\right)^{-1}$ and to $\mathrm{C}_{\mathrm{W}}=2.71 \times 10^{-4}\left(1 \cdot \mathrm{s}^{-1}\right)^{2} \cdot\left(\mathrm{cm}^{4} \cdot \mathrm{m}^{2} \cdot \mathrm{s}^{-2}\right)^{-1}$ respectively. These values are in accordance with the recommendations of the ASHRAE Handbook of Fundamentals 2001 (ASHRAE, 2001) when considering a stack effect developed within a height of one floor and a typical sheltering caused by other buildings across the street (third class of sheltering). These coefficients are finally multiplied for the corresponding hourly internal-external temperature difference $\Delta \mathrm{T}(\mathrm{K})$ and wind velocity $\mathrm{w}\left(\mathrm{m} \cdot \mathrm{s}^{-}\right.$ $\left.{ }^{1}\right)$.

As concerns internal gains, they are made up of four people involved in sedentary activities (releasing around $100 \mathrm{~W}$ each), and to the artificial lighting system releasing approximately $4 \mathrm{~W}$ per unit floor area.

As concerns the HVAC systems, they are supposed to be available according to the following schedules:

- Heating: from 7 am to 8 am and from 6 pm to 10 pm during winter (from December $1^{\text {st }}$ to March $31^{\text {st }}$ ), at a set-point temperature of $20{ }^{\circ} \mathrm{C}$;

- Cooling: from 9 am to 9 pm during summer (from June $1^{\text {st }}$ to September $30^{\text {th }}$ ), at a set-point temperature of $26^{\circ} \mathrm{C}$

In order to calculate the energy consumption of the heating system with OpenStudio, a Coil Heating Water Baseboard Radiant object is attributed to each thermal zone. These objects work at rated average water temperature and mass flow rate of $75{ }^{\circ} \mathrm{C}$ and $0.063 \mathrm{~kg} \cdot \mathrm{s}^{-1}$ respectively, and their capacity is auto sized by the software in order to always meet the heating load (DOE, 2018). The same auto-sizing principle applies to the heat-generator fed by natural gas (thermal efficiency = $90 \%$ ), which is used to produce the hot water needed by the baseboards, and to the circulation pump, whose efficiency is set to $70 \%$. As for the split units used to provide space cooling, the auto sized Packaged Terminal Heat Pump (PTHP) object with a nominal EER $=3$ is used.

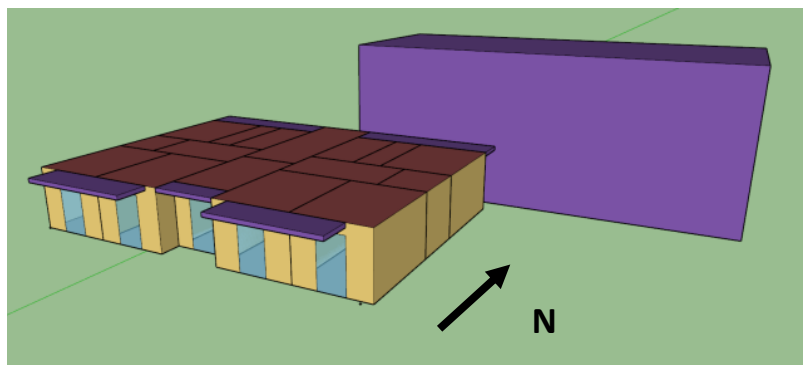

Figure 3: Axonometric view of the model in OpenStudio, including the shading surfaces (in purple) 


\section{Exergy calculations}

A recent literature review carried out by the authors about the exergy analysis in buildings (Evola et al., 2018) showed that the exergy related to a heat flux $Q$ available at a certain temperature $T$ can be calculated as:

$$
\mathrm{EX}=\mathrm{Q} \cdot\left(1-\frac{\mathrm{T}_{0}}{\mathrm{~T}}\right)
$$

Here, $T_{0}$ is the reference temperature, that is to say the temperature associated with the dead state. The term in brackets can be regarded as a quality factor, i.e. a measure of the exergy content related to a unit heat flux.

On the other hand, a different formulation has to be used to calculate the exergy lost by a mass flow m of a fluid, with specific heat at constant pressure $\mathrm{C}_{\mathrm{p}}\left(\mathrm{J} \cdot \mathrm{kg}^{-1} \cdot \mathrm{K}^{-1}\right)$, undergoing a temperature drop from $\mathrm{T}_{1}$ to $\mathrm{T}_{2}$ :

$$
\mathrm{EX}=\dot{\mathrm{m}} \cdot \mathrm{c}_{\mathrm{p}} \cdot\left\lfloor\left(\mathrm{T}_{2}-\mathrm{T}_{1}\right)-\mathrm{T}_{0} \cdot \ln \left(\frac{\mathrm{T}_{2}}{\mathrm{~T}_{1}}\right)\right\rfloor
$$

In this paper, Eq. (3) is used to calculate the exergy of the heat delivered to the indoor spaces by the heating terminal devices (or the exergy of the heat extracted from the indoor spaces by the cooling terminal devices). This is calculated by knowing the heat flux Q resulting from the dynamic simulations, whereas the indoor temperature is $\mathrm{T}=20{ }^{\circ} \mathrm{C}$ and $\mathrm{T}=26{ }^{\circ} \mathrm{C}$, respectively, when the heating and the cooling systems are in operation. Equation (3) is also formally used to calculate the exergy content of the heat transferred from the indoor spaces to the outdoor environment (or vice versa in summer), which is actually null since $\mathrm{T}=\mathrm{T}_{0}$.

Instead, Equation (4) is used to calculate the exergy transferred from the heat generator to the hot water and from the hot water to the indoor spaces through the baseboards. However, since the heat losses in the distribution network has been neglected for the sake of simplification, these two quantities are the same in this study.

Both calculations are carried out twice, by considering two different reference state conditions:

1. a constant reference temperature corresponding to the lowest outdoor air temperature in winter $\left(\mathrm{T}_{0}=\right.$ $-1.9^{\circ} \mathrm{C}$ ) for space heating, and to the highest outdoor air temperature in summer $\left(\mathrm{T}_{0}=35^{\circ} \mathrm{C}\right)$ or space cooling;

2. the hourly variable outdoor air temperature as recorded in the TMY weather file.

This is particularly relevant when dealing with exergy analysis, since there is no agreement by now within the scientific community concerning the choice of a common reference state for exergy calculations, as pointed out in (Evola et al., 2018). Some authors state that a variable reference temperature would lead to a series of thermodynamic contradictions (Pons, 2009); however, even when a constant reference temperature is used, this is chosen quite arbitrarily (Marletta, 2010; Sangi and Muller, 2016).

Moreover, the exergy contained in the fuel burnt by the gas-fired heat generator corresponds to its Lower Heating Value. The rate of fuel burnt by the heat generator is calculated by the software as a function of the thermal power delivered to the rooms, and accounting for the thermal efficiency $\eta=90 \%$.

On the other hand, when the HVAC system is fed by electricity, as for split-type units or electric air-to-water heat pumps, one has to consider that electricity is pure exergy. In this case, the exergy consumption is meant as the electricity needed to feed the compressor. Auxiliary systems such as pumps and fans are computed separately to evaluate their impact on the final exergy consumption.

However, electricity is produced in a power plant: hence, the exergy associated with the primary source deployed in the power plant $\left(\mathrm{EX}_{\mathrm{PS}}\right)$ can be calculated by dividing the electricity consumption $\left(\mathrm{E}_{\mathrm{EL}}\right)$ by the average efficiency of the power plant, here assumed to be of 51 $\%$ (UNI, 2014):

$$
\mathrm{EX}_{\mathrm{PS}}=\frac{\mathrm{E}_{\mathrm{EL}}}{0.51}
$$

Finally, starting from the values of the exergy fluxes it has been possible to calculate the exergy efficiency of the heating and cooling systems. This is the ratio of the useful exergy output (i.e. the exergy delivered to the indoor space) to the overall exergy input:

$$
\eta_{\mathrm{E}}=\frac{\mathrm{EX}_{\mathrm{us}}}{\mathrm{EX}_{\mathrm{in}}}
$$

In Eq. (6), the exergy input in the denominator also includes the primary exergy deployed to produce the electricity needed by the pumps in the heating loop and the fans for cooling operation, whose nominal electric power is $\mathrm{P}_{\text {pump }}=66 \mathrm{~W}$ and $\mathrm{P}_{\text {fan }}=35 \mathrm{~W}$, respectively.

\section{Results and discussion}

\section{Base case: the actual building}

As one would expect, the analysis of the base case scenario reveals poor energy performance for the selected apartment. This is mainly due to the poorly insulated envelope, which implies high heat fluxes exchanged with the outdoor environment, and to the use of low-efficiency HVAC systems. The final heating and cooling energy demand amount to around $12.8 \mathrm{kWh} \cdot \mathrm{m}^{-2}$ and $15.3 \mathrm{kWh} \cdot \mathrm{m}^{-2}$ respectively; the auxiliary devices (i.e. the circulation pump in the heating plant and the fans in the PTHP units for cooling operation) show an energy demand of $0.61 \mathrm{kWh} \cdot \mathrm{m}^{-2}$ and $0.73 \mathrm{kWh} \cdot \mathrm{m}^{-2}$, respectively.

The corresponding exergy fluxes during heating and cooling operation are shown in Figure 4 by adopting a cascading principle, i.e. from the primary energy source represented on the left-hand side of the graph, to the thermodynamic sink (i.e. the outdoor air) on the right- 
hand side. The contribution of the auxiliary devices to the primary exergy depletion is reported within a box.

From this kind of representation, many additional aspects can be appraised compared to a classic energy analysis. In a first instance, a decreasing trend for the exergy fluxes is observed, due to the degradation of the energy quality during its conversion processes. This is particularly evident when thermal energy is provided by means of a combustion process, as in the case of the heating system. Indeed, with respect to an amount of exergy of about $0.9 \mathrm{kWh} \cdot \mathrm{m}^{-2}$ delivered to the indoor spaces, the exergy consumption from the primary source (associated with the fuel and including also the circulation pump) is of around $15.4 \mathrm{kWh} \cdot \mathrm{m}^{-2}$. This results in a low exergy efficiency $\left(\eta_{\mathrm{E}}=5.7 \%\right)$ when considering a constant reference temperature, or even $\eta_{\mathrm{E}}$ $=2.9 \%$ with variable reference temperature.

Secondly, the exergy delivered to the indoor spaces by the cooling system is much lower than for the heating process $\left(0.4 \mathrm{kWh} \cdot \mathrm{m}^{-2}\right.$ against $\left.0.9 \mathrm{kWh} \cdot \mathrm{m}^{-2}\right)$. This happens because in summer the reference state conditions are very close to the cooling set-point temperature of $26^{\circ} \mathrm{C}$ used in the simulations. Therefore, the resulting exergy efficiency for space cooling is only $\eta_{\mathrm{E}}=3.2 \%$ when considering a fixed outdoor temperature for the reference state, and $\eta_{\mathrm{E}}=0.7 \%$ with a variable reference temperature.

Lastly, it is apparent that the choice of the reference state conditions does significantly affect the calculation of the exergy fluxes for cooling: the difference between the results obtained under the two different assumptions is around $46 \%$. On the other hand, this difference amounts to around $17 \%$ in the case of space heating.

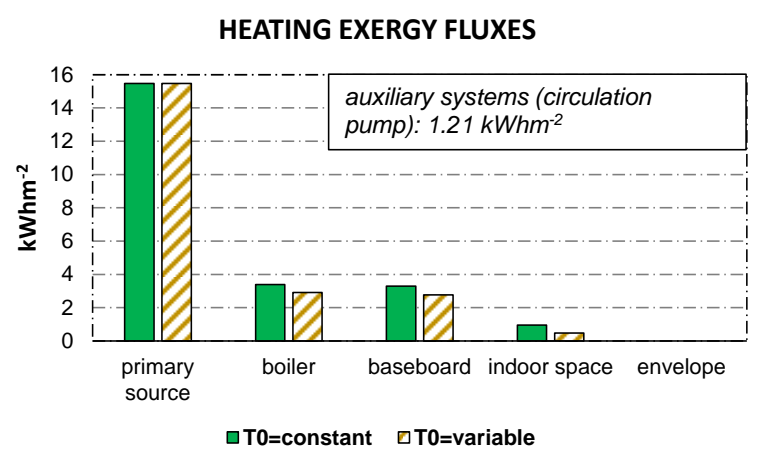

COOLING EXERGY FLUXES

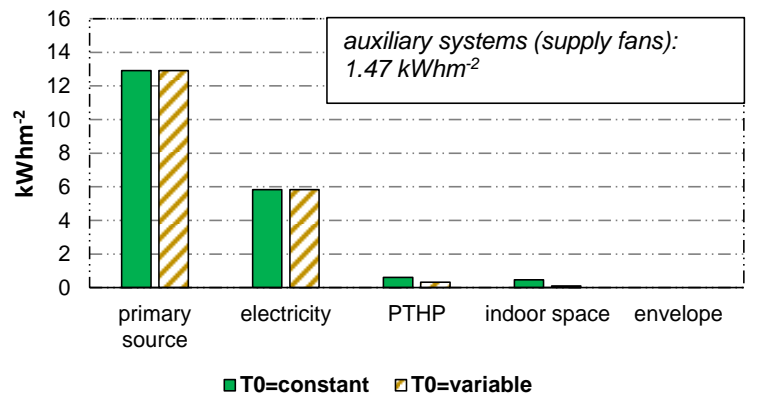

Figure 4: Heating and cooling exergy fluxes for the base case

\section{Retrofit scenario 1: improved envelope insulation}

The first retrofit scenario simulates a basic improvement in the insulation level of the envelope, aimed to comply with the actual prescriptions set by the Legislative Decree 26/06/2015 (Legislative Decree 26/06/2015, 2015). This norm prescribes maximum acceptable Uvalues for the building envelope components as a function of the climate zone in which the building is located. For the city of Catania, the maximum U-value is $0.43 \mathrm{~W} \cdot \mathrm{m}^{-2} \cdot \mathrm{K}^{-1}$ for the external walls and $3.0 \mathrm{~W} \cdot \mathrm{m}^{-2} \cdot \mathrm{K}^{-1}$ for the windows, respectively. The proposed retrofit solution simulates the application of a $4-\mathrm{cm}$ thick layer of extruded polystyrene (XPS) as insulating material to the outer side of the external walls, which results in $\mathrm{U}=$ $0.40 \mathrm{~W} \cdot \mathrm{m}^{-2} \cdot \mathrm{K}^{-1}$, and the replacement of the original single-glazed windows with double-glazed low-emissive ones showing $\mathrm{U}=1.82 \mathrm{~W} \cdot \mathrm{m}^{-2} \cdot \mathrm{K}^{-1}$. In this first retrofit scenario, the HVAC systems are kept the same as in the base case, in order to appreciate the role played by the envelope only in the exergy performance of the building.

The results of this set of simulations show that the heating energy demand can be almost halved, decreasing from $12.8 \mathrm{kWh} \cdot \mathrm{m}^{-2}$ in the base case to $7.4 \mathrm{kWh} \cdot \mathrm{m}^{-2}$ for the retrofit scenario. On the other hand, the cooling energy demand slightly increases from $15.3 \mathrm{kWh} \cdot \mathrm{m}^{-2}$ to $15.5 \mathrm{kWh} \cdot \mathrm{m}^{-2}$, because of the improved insulation and the lack of additional passive cooling measures that may help releasing the heat outside.

The resulting exergy fluxes for this scenario are reported in Figure 5 in the same fashion as for the base case. What is immediately visible is the strong reduction in the primary exergy consumption (fuel) for space heating, from $15.4 \mathrm{kWh} \cdot \mathrm{m}^{-2}$ in the base case (Fig. 4) to 7.7 $\mathrm{kWh} \cdot \mathrm{m}^{-2}$ in the retrofit scenario (Fig. 5). This happens because the exergy demand of the indoor space is now $0.47 \mathrm{kWh} \cdot \mathrm{m}^{-2}$ against $0.9 \mathrm{kWh} \cdot \mathrm{m}^{-2}$ in the existing scenario (under the assumption of constant outdoor reference temperature). Furthermore, the exergy demand for the circulation pump decreases from $1.21 \mathrm{kWh} \cdot \mathrm{m}^{-2}$ (Fig. 4) to $0.80 \mathrm{kWh} \cdot \mathrm{m}^{-2}$ (Fig. 5), thanks to the reduced activation time of the gas-fired heat generator. In terms of exergy fluxes for space cooling, they keep almost the same value as for the base case. The only exception is the reduction in the exergy demand of the supply fans from $1.47 \mathrm{kWh} \cdot \mathrm{m}^{-2}$ (Fig. 4) to $1.38 \mathrm{kWh} \cdot \mathrm{m}^{-2}$ (Fig. 5), mainly due to the reduction of the peak cooling load coming from the improved insulation.

However, despite the improvements achieved in the heating season, the exergy efficiency of this scenario is practically the same as that pertaining to the base case (see Table 3). This implies that, from an exergy point of view, further improvements are needed to make a more rational use of the (reduced) amount of energy needed to keep comfortable conditions indoors. Finally, also in this case the choice of different reference conditions impacts on the results in terms of exergy fluxes for about $17 \%$ in the case of space heating and for around $47 \%$ in the case of space cooling. 


\section{HEATING EXERGY FLUXES}

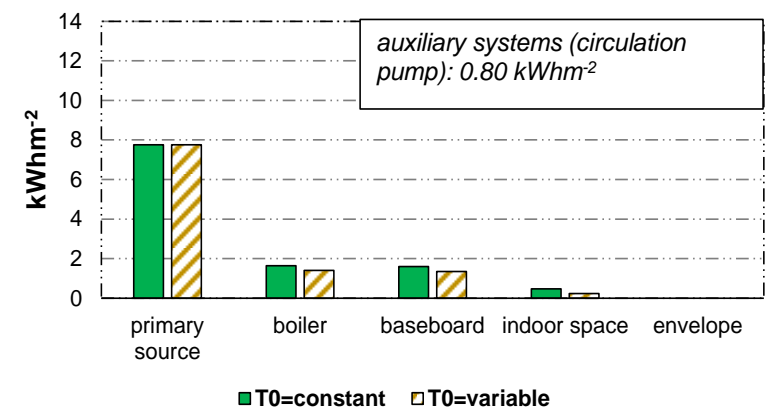

COOLING EXERGY FLUXES

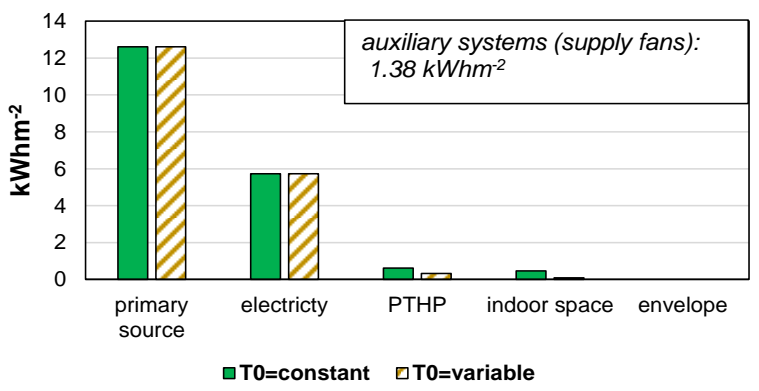

Figure 5: Heating and cooling exergy fluxes for the first retrofit scenario

\section{Retrofit scenario 2: more efficient HVAC systems}

The second retrofit scenario considers the combined effect of using more insulated envelope components while adopting more energy efficient HVAC systems. The only difference with the Retrofit scenario 1 is thus given by the use of high-performing air-to-air PTHP units for providing both space heating and cooling. In this scenario, both the nominal Coefficient of Performance (COP) in heating mode and the Energy Efficiency Ratio (EER) in cooling mode are set to 5 in OpenStudio, although the average working COP and EER turned out to be 3.8 and 4.2, respectively, because of the fluctuations of the outdoor air temperature that reduce the efficiency of the device.

Under these circumstances, the energy demand for heating and cooling is the same as for the previous retrofit scenario $\left(7.4 \mathrm{kWh} \cdot \mathrm{m}^{-2}\right.$ and $15.5 \mathrm{kWh} \cdot \mathrm{m}^{-2}$ in order), thus rebating the importance of using building components with lower U-values for reducing the magnitude of the heat fluxes through the envelope.

However, the use of the PTHP devices for providing space heating in place of the baseboards significantly reduces the exergy fluxes from the primary source to the indoor space (see Fig. 6). In fact, although the exergy demand of the indoor space and of the auxiliary systems keeps the same as for the previous retrofit scenario, the exergy consumption linked to the primary energy sources from the power plant now amounts to 4.7 $\mathrm{kWh} \cdot \mathrm{m}^{-2}$ in the case of space heating and to $8.3 \mathrm{kWh} \cdot \mathrm{m}^{-2}$ in the case of space cooling. These values are significantly lower than those of the Retrofit scenario 1, which amount to $7.7 \mathrm{kWh} \cdot \mathrm{m}^{-2}$ and $12.6 \mathrm{kWh} \cdot \mathrm{m}^{-2}$ respectively. This helps improving the exergy efficiency significantly with respect to the base case, as can be seen in Table 3. Here, the exergy efficiency is almost doubled (from $5.7 \%$ to $9.8 \%$ ) in the case of space heating thanks to the adoption of a different and more "rational" process for producing low-grade heat (i.e. an electric heat pump rather than a combustion process). Noticeable improvements should be expected in the case of space cooling as well, where under a fixed reference temperature a raise in the efficiency from $3.2 \%$ to $4.8 \%$ is predicted, while under varying reference temperature the improvement with respect to the base case is from $0.7 \%$ to $0.9 \%$ only. Here it is worth to notice that adopting a very efficient PTHP unit just slightly reduces the electricity demand and, as such, is barely justifiable if not coupled with the implementation of some passive cooling measures.

Finally, the exergy fluxes evaluated according to constant reference state conditions for this scenario are about $40 \%$ higher than those evaluated with varying reference state temperatures, whereas in the case of cooling this difference is slightly higher and amounts to around $48 \%$.

\section{HEATING EXERGY FLUXES}

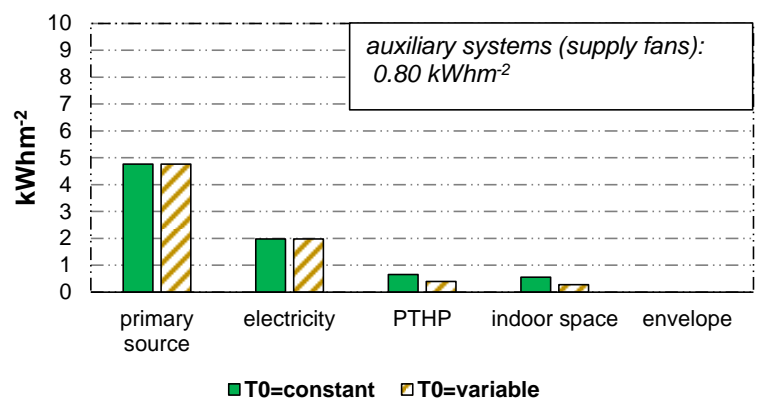

COOLING EXERGY FLUXES

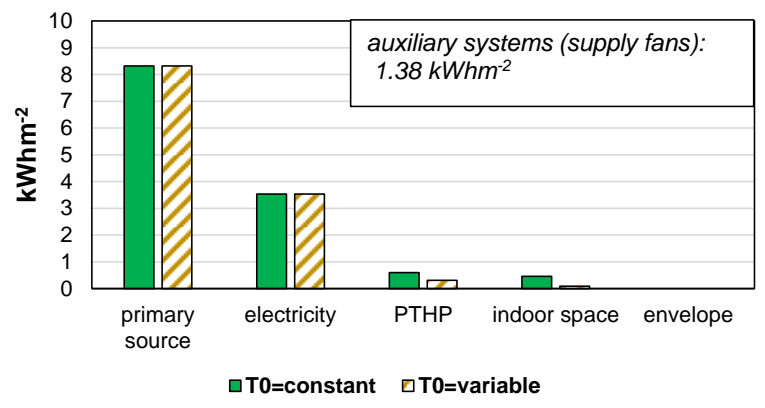

Figure 6: Heating and cooling exergy fluxes for the second retrofit scenario

Table 3: Variation of the exergy efficiency with the choice of the reference temperature (dead state)

\begin{tabular}{c|cc|cc}
\hline \multirow{2}{*}{ Scenario } & \multicolumn{2}{|c|}{$\mathbf{T}_{\mathbf{0}}=$ constant } & \multicolumn{2}{c}{$\mathbf{T}_{\mathbf{0}}=$ variable } \\
\cline { 2 - 5 } & Heating & Cooling & Heating & Cooling \\
\hline Base case & $5.7 \%$ & $3.2 \%$ & $2.9 \%$ & $0.7 \%$ \\
Retrofit scenario 1 & $5.7 \%$ & $3.2 \%$ & $2.9 \%$ & $0.7 \%$ \\
Retrofit scenario 2 & $9.8 \%$ & $4.8 \%$ & $5.1 \%$ & $0.9 \%$ \\
\hline
\end{tabular}




\section{Conclusions and remarking points}

This paper proposed the exergy analysis of a typical multi-apartment block located in Catania (Italy), a city characterized by hot and humid climate conditions. The investigation is based on the combination of the First and the Second Law of Thermodynamics; this provides information about the rational use of energy in space heating and cooling systems in buildings.

The application of typical retrofit interventions, based on improving the insulation level of the envelope and on using more energy-efficient HVAC systems, allowed reducing the energy demand for space heating by about $50 \%$ from the base case (i.e. from $12.8 \mathrm{kWh} \cdot \mathrm{m}^{-2}$ to 6.2 $\mathrm{kWh} \cdot \mathrm{m}^{-2}$ ). On the other hand, the energy needs for space cooling keep very close to the base case (i.e. around 15.3 $\mathrm{kWh} \cdot \mathrm{m}^{-2}$ ). This can be explained considering that, for the specific climate analysed, the implementation of passive cooling measures during summer should be pursued in order to reduce cooling loads.

When complementing this classic energy analysis with an exergy analysis, several thermodynamic inefficiencies can be identified that would be otherwise overlooked. In fact, the estimation of the exergy fluxes for every element of the supply chain - from the primary energy use to the thermodynamic sink - can better inform the choice of different retrofit options.

With regard to the case study, the use of heating devices driven by electricity and with high conversion efficiency (COP), rather than based on a combustion process, contributes to make a more rational use of energy. This is demonstrated by the reduced exergy needs for keeping the indoor space at the set point temperature of $20{ }^{\circ} \mathrm{C}$ $\left(0.55 \mathrm{kWh} \cdot \mathrm{m}^{-2}\right.$ against $\left.0.96 \mathrm{kWh} \cdot \mathrm{m}^{-2}\right)$ and by the higher exergy efficiency achieved $(9.8 \%$ against $5.7 \%)$.

In the case of space cooling, although as mentioned above the cooling needs keep pretty much the same as in the existing scenario, the use of very performing Packaged Terminal Heat Pump (PTHP) units allows to reduce drastically the primary exergy demand. This now amounts to $8.3 \mathrm{kWh} \cdot \mathrm{m}^{-2}$ when the nominal Energy Efficiency Ratio is EER $=5$, against a value of 12.6 $\mathrm{kWh} \cdot \mathrm{m}^{-2}$ when EER $=3$.

Furthermore, the primary exergy demand related to the supply fans decreases as well, from $1.47 \mathrm{kWh} \cdot \mathrm{m}^{-2}$ to $1.38 \mathrm{kWh} \cdot \mathrm{m}^{-2}$ namely. These effects work synergically in reducing the exergy consumption from primary sources, thus improving the exergy efficiency from 3.2 $\%$ (base case) to $4.8 \%$.

One can also observe that, in the best scenario, the exergy consumption for the auxiliary systems becomes a considerable item, being around $17 \%$ of the total exergy consumption. This suggests that in low-exergy systems the use of efficient auxiliary devices is needed.

What seems to represent a barrier to a wider application of the exergy analysis to buildings and energy systems is the lack of a common agreement around the definition of the reference conditions. In this paper, the exergy fluxes have been calculated with respect to two different reference state conditions (constant and variable outdoor air temperatures namely), and differences up to $48 \%$ should be expected in the results. Efforts in the definition of internationally recognized calculation methods should thus be pursued to allow for consistent comparison amongst different design options.

\section{Acknowledgements}

The work described in this paper was carried out within the project "Research for SEAP: a platform for municipalities taking part in the Covenant of Mayors", financed by Italian Government in the framework of PRIN 2015.

\section{References}

ASHRAE, ASHRAE Handbook Fundamentals, American Society of Heating, Refrigerating and AirConditioning Engineers, Inc., Atlanta, 2001

Legislative Decree 26/06/2015, Updates of the guidelines for the energy certification of buildings

DOE, EnergyPlus energy simulation software, 2018 (Accessed 14 December 2018). https://energyplus.net/.

Evola G., Costanzo V., Marletta L. (2018). Exergy analysis of energy systems in buildings. Buildings 8(12), 180.

Kazanci, O.B., Shukuya, M., Olesen, B.W. (2016). Exergy performance of different space heating systems: a theoretical study. Building and Environment 99, 119-129.

Marletta, L. (2010) Air conditioning systems from a 2nd Law perspective. Entropy 12, 859-877.

Pons, M. (2009). On the reference state for exergy when ambient temperature fluctuates. International Journal of Thermodynamics 12, 113-121.

Sangi, R., Müller, D. (2016). Exergy-based approaches for performance evaluation of building energy systems. Sustainable Cities and Societies 2016, 25, 25-32.

Schmidt, D. Low exergy systems for high-performance buildings and communities. ECBCS Annex 49 final report, 2011. Available at https://www.annex49.info/background.html.

UNI 11300:1 (2014), Thermal Performances of buildings - Part 1: Estimate of the energy needs of buildings for space heating and cooling

Zhou, Y., Gong, G. (2013). Exergy analysis of the building heating and cooling system from the power plant to the building envelop with hourly variable reference state. Energy and Buildings 56, 94-99. 